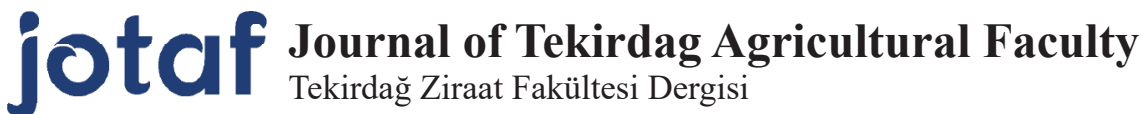

Mayıs/May 2019, 16(2) Basvuru/Received: 13/03/19 Kabul/Accepted: 16/04/19 DOI: $10.33462 /$ jotaf.539332

http://dergipark.gov.tr/jotaf http://jotaf.nku.edu.tr/

\section{Edirne İlinde Depolanmış Buğday ve Un Fabrikalarında Saptanan Zararlı Böcekler Üzerine Araștırmalar*}

Investigation on Insect Pest Species in Grain Warehouse and Flour Mills in Edirne Province

\author{
Oktay TOĞANTIMMUR ${ }^{1}$, Nihal ÖZDER ${ }^{2 * *}$
}

\section{$\ddot{O} \mathbf{z}$}

Bu çalışma Edirne İlinde depolanmış buğday ve un fabrikalarında bulunan zararlı böceklerin saptanması amacıyla 2017 - 2018 yılları arasında yürütülmüştür. 8 zahireci deposu, 5 un fabrikası ve 3 adet TMO deposundan ayda bir kez buğday, un ve kepek örnekleri alınmıştır. Sürvey sonucunda Sitophilus granarius (L.), Sitophilus oryzae (L.), Tribolium confusum (Duv.), Tribolium castaneum (Herbst), Ephestia kuehniella (Zell.), Plodia interpunctella (Hübner), Rhizopertha dominica (F.), Oryzaephilus surinamensis (L.), Gnathocerus cornutus (Fab.), Cryptolestes ferrugineus (Stephens 1831), Carpophilus dimidiatus (Fabricius, 1792) fabrikalarda bulunan zararlı böcekler olarak saptanmıştır.

Anahtar Kelimeler: Buğday, un, kepek, depolama, zararlı böcekler

\begin{abstract}
This study was carried out in order to define in stored wheat and flour mills on insect pests species in Edirne in the years of 20172018. Wheat, flour and bran samples were collected from in total 16 grain store and mills monthly. The results obtained from this study indicated that Sitophilus granarius (L.), Sitophilus oryzae (L.), Tribolium confusum (Duv.), Tribolium castaneum (Herbst), Ephestia kuehniella (Zell.), Plodia interpunctella (Hübner), Rhizopertha dominica (F.), Oryzaephilus surinamensis (L.), Gnathocerus cornutus (Fab.), Cryptolestes ferrugineus (Stephens 1831), Carpophilus dimidiatus (Fabricius, 1792) were defined as insect pests in storages and mills insect pests of stored wheat and flour.
\end{abstract}

Keywords: Wheat, flour, bran, storage, insect pests

\footnotetext{
${ }^{1}$ Oktay Toğantimur, Tarım Orman Bakanlığı Süloğlu ilçe Gıda Tarım ve Hayvancılık Müdürlüğü, E-mail: oktay.togantimur@tarimorman.gov. tr (iD OrcID: 0000-0003-3813-6715

2**Sorumlu Yazar/Corresponding Author: Nihal Özder, Namık Kemal Üniversitesi, Ziraat Fakültesi, Bitki Koruma Bölümü, Tekirdağ, E-mail: nozder@ku.edu.tr(D) OrcID: 0000-0002-4637-5364

Atıf/Citation: Toğantimur, O., Özder N. Edirne ilinde depolanmış buğday ve un fabrikalarında saptanan zararlı böcekler üzerine araştırmalar. Tekirdă Ziraat Fakültesi Dergisi, 16(2), 192-201.

* Bu çalışma Oktay Toğantimur'un yüksek lisans tezinden hazırlanmıştır.
} 


\section{Extendend Summary}

This study was carried out in order to define insect pest species in stored wheat and flour mills in Edirne in the years of 2017-2018. Wheat, flour and bran samples were monthly collected from in total 8 grain store, 5 mills and 3 TMO stores. . Sampling store (Z1, Z2, Z3, Z4, Z5, Z6, Z7, Z8) and wheat store of flour factory (U1, U2, U3, U4, U5). From the dandruff in flour factories and randomly selected sacks of bags stored in sacks were taken from the taken separately $1 \mathrm{~kg}$ sapmles. Samples taken from each factory were taken into polyethylene bags and labels included. Samples in polyethylene bags were sieved. Material under and above the sieve is examined in detail. Obtained adults were killed in the killing bottle and their numbers were recorded. Then each sample was put into glass jars. To prevent insects from escaping, glass jars are covered with tulle. Glass jars for three months were checked once a week to collect adult insects. The controls continued until the adult exits, then samples were identified and their numbers recorded. As the result of survey, Sitophilus granarius (L.), Sitophilus oryzae (L.), Tribolium confusum (Duv.), Tribolium castaneum (Herbst), Ephestia kuehniella (Zell.), Plodia interpunctella (Hübner), Rhizopertha dominica (F.), Oryzaephilus surinamensis (L.), Gnathocerus cornutus (Fab.), Cryptolestes ferrugineus (Stephens 1831), Carpophilus dimidiatus (Fabricius, 1792) were determined as insect pests in storages and mills. This survey showed that all of the store, flour factories and miles were infested by insect species. Sitophilus granarius, Sitophilus oryzae, Tribolium castaneum and Tribolium confusum were more common and dense species. The greatest percentages of the pest were observed in the mills. The greatest percentage of the adults was noted in U1 among the store, flour factory and mils. The highest level of population was determined during the august and the lowest population was determined in the february. Cereals grains are the major source of food for human. S. granarius and S. oryzae is the most important primary pest of stored wheat. According the our study and other study these pests were very common in Bursa, Adıyaman, Kahramanmaraş, Erzurum, Bayburt, Erzincan and Ankara in Turkey Bağc1 et al. 2014, Coşkuncu, 2004, Işıkber et al. 2005, Özdemir 2015). Results of this study, indicates that insect population generally increased depending on temperature and sanitation. Finally we suggested to prevent infestation by insect pest by sanitation. 
Tahıllar grubu olarak adlandırdığımız kültür bitkileri; buğday (Triticum), arpa (Hordeum), yulaf (Avena), çavdar (Secale), mısır (Zea), çeltik (Oryza), darılar (Sorghum, Panicum, Seteria), kuşyemi (Phalaris) ekiliş, üretim ve kullanım yönünden tarla bitkileri içinde çok önemli bir yere sahiptir (Gençtan ve Balkan 2005).

Güneybatı Asya orijinli olan buğdayın Türkiye, Suriye, Irak ve Kafkasya'da yabani türleri bulunmaktadır ve buralar buğdayın gen merkezi olarak kabul edilmektedir (Kırtok 1997).

İnsan sağlığında önemli etkisi bulunan A, C, E, K, B6 ve B12 vitaminleri, demir, kalsiyum, fosfor ve magnezyum açısından zengin olan buğday, un ve unlu mamuller, makarna, irmik, bisküvi, bulgur olarakta tüketilmektedir. Buğday ülkelerin stratejik öneme sahip bitkileri olarak değerlendirilmektedir.

Türkiye yüzölçümünün \%29,7'si tarım yapılabilir özelliktedir. Türkiye tarım anlamlarının büyük bir kısmı tarla ziraatına ayrılmış olup, bu alanın da yaklaşı \% 71'inde (11,1 milyon hektar) hububat ekilmektedir. Hububat ekim alanı içerisinde buğday \%69'lik payla ilk sırada yer almaktadır. (Anonim 2018).

Dünya nüfusunun hızla artması buna karşın kullanılabilir tarım alanlarının gittikçe azalması nedeni ile dünya nüfusunun yeterli beslenmesi büyük sorun olmaktadır. Araştırıcılar pek çok faktöre bağlı olan tarımsal üretimde birim alandan daha fazla ürün alabilmek için çalışmalar yürütmektedir. Tarımsal üretim aşamasının yanı sıra uygun olmayan depolama koşulları nedeni ile de önemli kayıplar meydana gelmektedir. Genellikle depolanmış ürünlerde hayvansal kökenli organizmaların neden olduğu kayıplar yıllık ortalama \%10 olarak kabul edilmektedir (Donahaye ve Messer 1992).

Depolanmış üründe zararlı böcekler ürünlerde belnerek meydana getirdikleri ağırlık kayıplarının yanı sıra besin değerinin, tohumluk özelliklerinin de düşmesine neden olmaktadırlar. Ayrıca beslenmeleri sırasında meydana getirdikleri salgılar, vücut artıkları ve pislikleri ile de insanlarda alerji astım gibi bazı hastalıkların oluşmasına neden olmaktadırlar. (Boxall 2001). Zararlıların artan populasyonları sonucunda ortamda artan nem ve sicaklıkla birlikte üründe küflenme, kızışma ve kokuşma gözlenmektedir. Bu ürünlerin tüketilmesi insan ve hayvanlarda önemli hastalıkların meydana gelişine neden olmaktadır. Örneğin Tribolium spp. (Col: Tenebrionidae) üründe kanserojen maddelerin oluşumuna neden olabilmektedir (Stejskal ve Hubert 2006).

Bu çalışmada ile önemli buğday üretimi,depolaması ve un fabrikasına sahip, Edirne İlinde depolanmış buğday ve un fabrikalarında zararlı böceklerin saptanması üzerine çalışılmıştır.

\section{Materyal ve Yöntem}

Çalışmanın materyalini Edirne ilinde depolarında yıl boyunca buğday bulunduran 8 adet zahireci deposu, 5 adet un fabrikası ile 3 adet TMO' ya ait kapalı depo ve açık yığınlar ile burada bulunan zararlılar oluşturmaktadır. Örnekleme yapılan zahirecilere ait depolar (Z1, Z2, Z3, Z4, Z5, Z6, Z7, Z8) ile un fabrikalarının buğday depoları (U1, U2, U3, U4, U5) isimlendirilmiş olup betonarme tiptedirler. Toprak Mahsülleri Ofisinin, Merkez ve Havsa'da betonarme ve modern açık yığın depolama ünitesinden (MAYDÜ), Lalapaşada ise modern açık yığın depolama ünitesinden MAYDÜ örneklemeler yapılmıştır. İlgili depo ve açık yı̆̆ınlarda zararlıların tespit edilmesi amacıyla 2017 yılı temmuz ayından 2018 yılı Mayıs ayına kadar ayda bir kez bahse konu yerlere gidilerek zahireci ve TMO depolarından buğday, un fabrikalarından ise buğday, un ve kepek örnekleri alınmıştır.

Un fabrikaları, zahireci depoları ve Toprak Mahsulleri Ofisine ait betonarme kapalı depo ile modern açık yığın depolama ünitelerinde buğday dökme olarak depolanmış olduğu için ürünün çeşitli yer, yön ve derinliklerinden alınan ürünler karıştırılarak paçal yapılmıștır. Paçal yapılan bu ürünlerden $1 \mathrm{~kg}$.' lık numuneler alınmıştır. Un fabrikalarında dökme olarak bulunan kepeklerden ve çuval halinde depolanan unlardan ise tesadüfi olarak seçilen çuvallardan ayrı ayrı alınan ürünlerden paçal yapılarak 1 kg.’ lık numuneler alınmıştır. Her fabrikadan alınan örnekler polietilen torbalara alınarak içlerine yer adı ve tarih gibi bilgileri içeren etiketler konulmuştur. Polietilen torbalardaki numuneler elenerek elek üstünde ve altında kalan materyal detaylı olarak incelenmiştir. Bulunan erginler öldürme şişesinde öldürülerek sayıları kaydedilmiştir. Daha sonra her numune tekrar cam kavanozlara konularak ağızları tül ile böcek çıkışına engel olacak şekilde kapatılmıştır. Üç ay boyunca haftada bir kez kontrol edilerek kavanozlardan çıkan ergin böcekler toplanmış ve sayıları her örnek için çıkan sayıya eklenmiştir. Ergin çıkışları bitinceye kadar gözlemlere devam edilmiştir. Daha sonra numunelerin teşhisleri yapılarak sayıları kayıt altına alınmıştır.

\section{Araştirma Bulguları ve Tartışma}

Yapılan çalışma sonucunda Edirne İlinde depolanmış buğday ve un fabrikalarında Coleoptera takımına ait 9 tür 
ve Lepidoptera takımına ait 2 tür olmak üzere 11 zararlı tür saptanmıştır.

\section{Edirne ilinde depolanmıș buğday ve un fabrikalarında saptanan zararlı böcek türlerinin bulunma oranları} (\%)

Edirne İlinde bulunan 8 adet zahireci ile 3 adet TMO deposundan alınan depolanmış buğday örnekleri ve 5 adet un fabrikasından alınan un, buğday ve kepek örneklerinin incelenmesi sonucu toplamda 11 zararlı tür tespit edilmiştir. Bu türler; Sitophilus spp. [Sitophilus granarius (L.), Sitophilus oryzae (L.)] \% 69,43, Tribolium spp. [Tribolium confusum (Du Val.), T. castaneum (Herbst.)] \% 13,21, Oryzaephilus surinamensis (L.) \%7,37, Ephestia kuehniella (Zell.) \% 6,45, Carpophilus dimidiatus \%1,84, Rhizopertha dominica (F.) \%1,08 ve diğer zararlılar [ Cryptolestes ferrugineus (Step.), Plodia interpunctella ve Gnathocerus cornutus (Fab.) ] \% 0.62 olarak belirlenmiştir. Yapılan çalışma sonucu Sitophilus türleri \% 69,43 ile bulunma oranları en fazla olan türler olarak belirlenmiştir (Şekil 1).

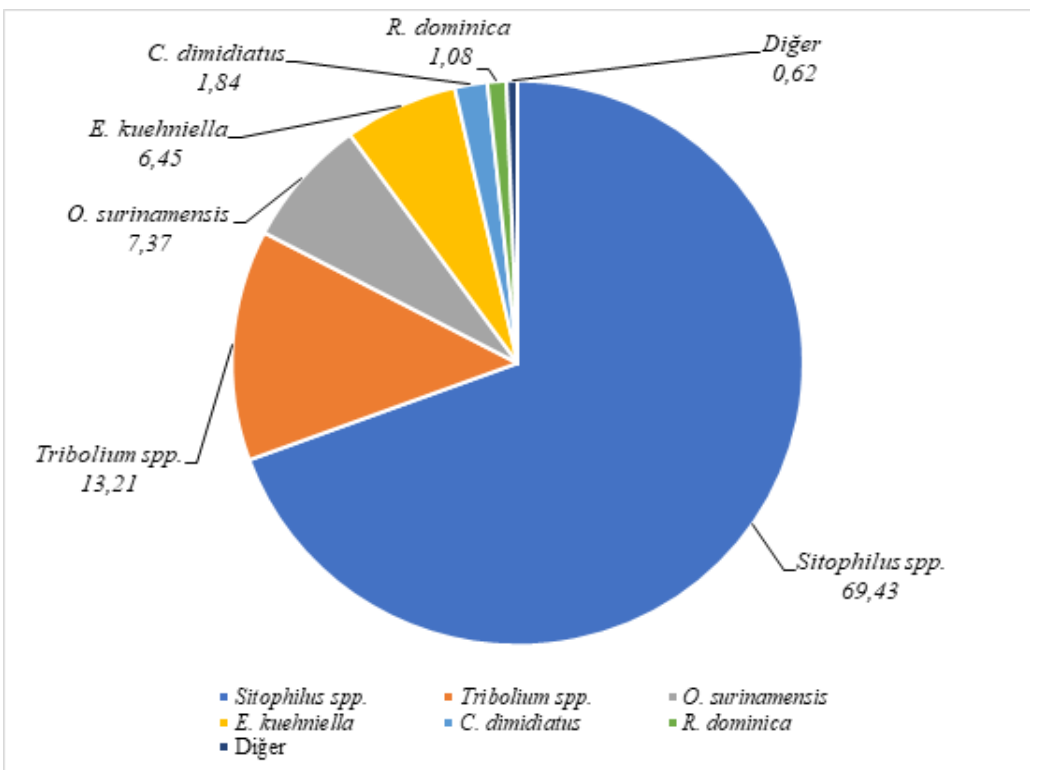

Şekil 1. Edirne ilinde buğday depoları ve un fabrikalarında saptanan zararlı böcek türlerinin bulunma oranları (\%)

Figure 1. Proportion of pests found in wheat warehouses and flour mills in Edirne province (\%)

Yapılan çalışmalar sonucunda, un fabrikalarında buğdayın yanı sıra yapılan un ve kepek örneklemeleri yapıldı ̆̆ için saptanan tür sayıları ve böceklerin sayıları zahireciler ve TMO depolarından alınan örneklere göre daha fazla bulunmuştur. (Şekil 2). 


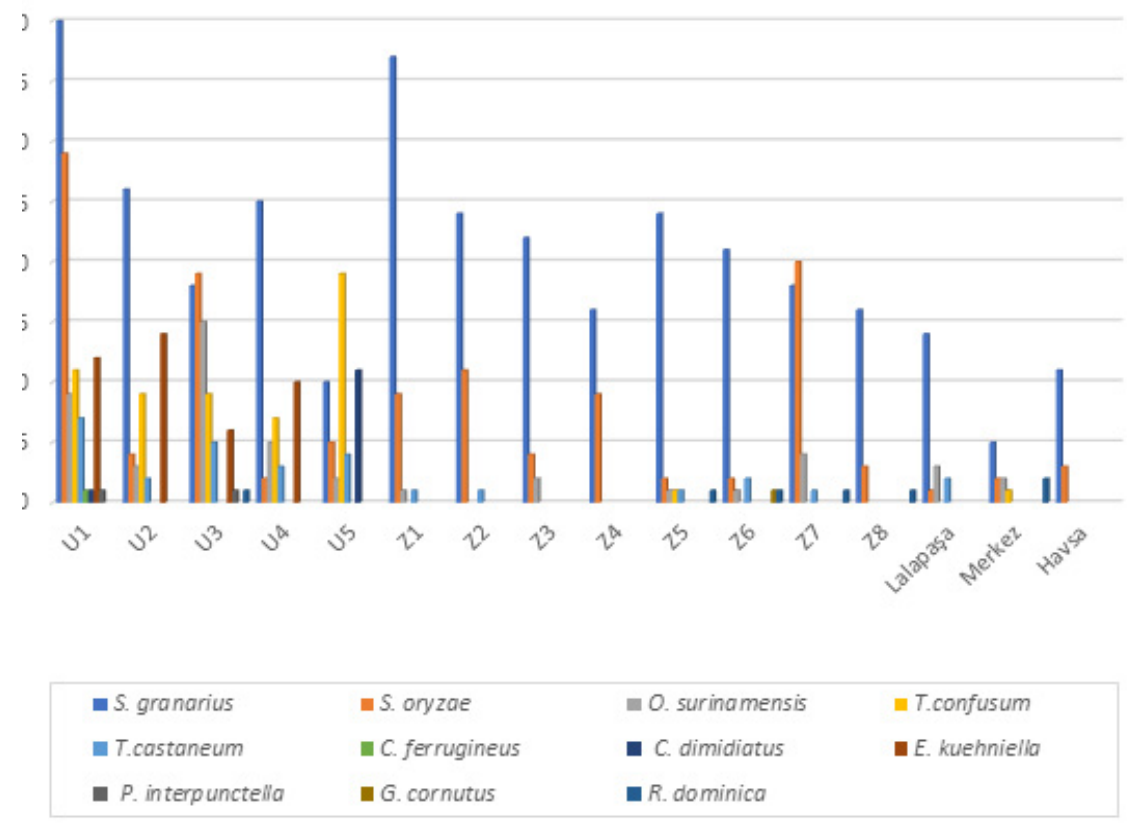

Şekil 2. Edirne ilinde buğday depoları ve un fabrikalarında saptanan zararlı böcek türlerinin depolara ve fabrikalara göre birey sayıları (adet/kg ürün)

Figure 2. Number of individuals according to warehouses and flour factories of pest insects detected in Edirne province (pieces / kg product)

Edirne İlinde depolanmış buğday ve un fabrikalarından yapılan survey sonucunda U1 nolu depo bulaşmanın en yoğun olduğu depo olarak belirlenmiştir. Daha sonra sirasiyla U3, U2, U4, U5, Z1, Z7, Z2, Z5, Z3 ile Z6, Z4, Z8 ile TMO Lalapaşa, TMO Havsa ve TMO Merkez depoları gelmektedir. Bu farklılığın, U1 nolu fabrikanın ürün giriş çıkışının en yoğun olduğu fabrika olması ve bölge fabrikaları içerisinde en büyük depolama alanına sahip olmasından kaynaklanabileceği düşünülmektedir.

Özdemir (2015) Erzurum, Bayburt, Erzincan'da Toprak Mahsulleri Ofisi’nin değişik değişik tiplerdeki hububat depolarında yapmış olduğu çalışmada Oryzaephilus surinamensis' in en yaygın tür olduğunu bildirmiştir

Gönen ve Uzunköprü ilçeleri çeltik depolarında yapılan bir çalışmada Sitophilus granarius Linnaeus (Coleoptera: Curculionidae), Sitophilus oryzae Linnaeus (Coleoptera: Curculionidae), ,Tribolium confusum Jacquelin du Val (Coleoptera: Tenebrionidae), Tribolium castaneum Herbst (Coleoptera: Tenebrionidae, Ephestia kuehniella Zeller (Lepidoptera: Pyralidae, Plodia interpunctella Hübner (Lepidoptera: Pyralidae; Sitotroga cerealella Olivier (Lepidoptera: Gelechiidae), Anthrenus verbasci Linnaeus (Coleoptera: Dermestidae), Rhyzopertha dominica Fabricius (Coleoptera: Bostrichidae), Alphitophagus bifasciatus Say (Coleoptera: Tenebrionidae), Oryzaephilus surinamensis Linnaeus (Coleoptera: Silvanidae), Carpophilus hemipterus Linnaeus (Coleoptera: Nitidulidae) ve Lasioderma serricorne Fabricius (Coleoptera: Anobiidae) (Atabay ve ark. 2013) olmak üzere on üç türün tesbit edildiği kaydedilmiştir. Yapılan çalışmada da saptanan türler arasında paralellik olduğu görülmektedir.

Edirne ilinde depolanmış buğday ve un fabrikalarında saptanan zararlı böceklerin aylara göre bulunma oranları

Zararlıların aylara göre bulunma oranlarına bakıldığında, zararlıların en yoğun ağustos ayında, en düşük yoğunluğun ise şubat ayında bulunduğu görülmektedir (Şekil 3). 


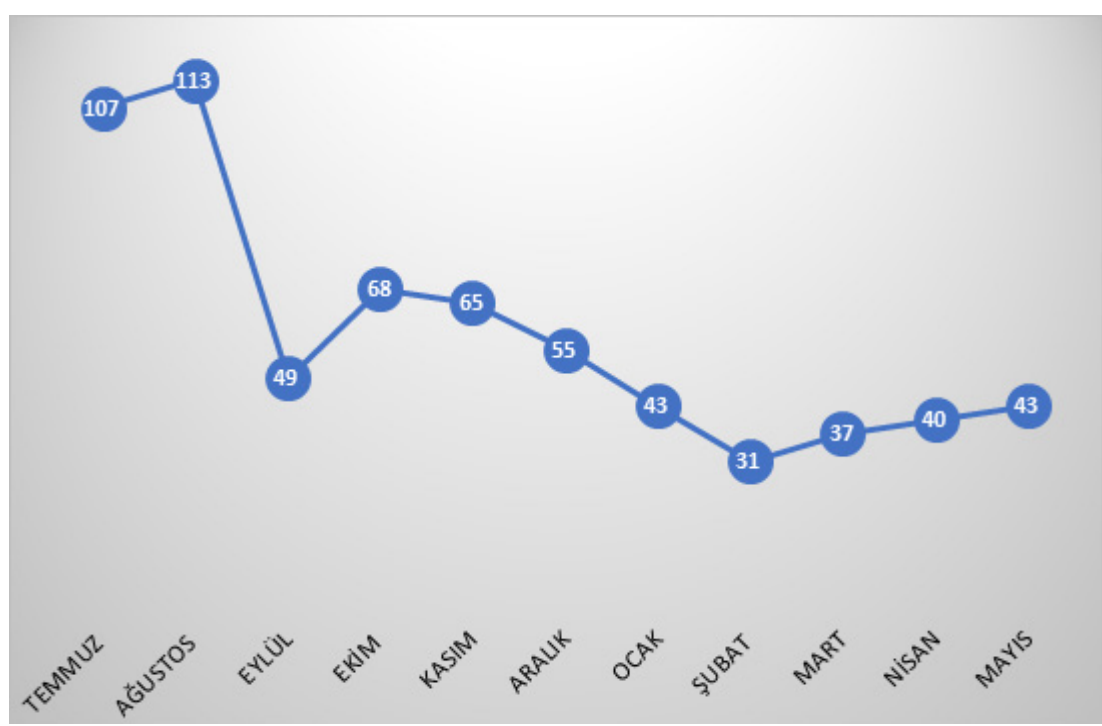

Şekil 3. Edirne ilinde buğday depoları ve un fabrikalarında saptanan zararlı böceklerin aylara göre bulunma oranları

Figure 3. Monthly rates of pest insects detected in wheat warehouses and flour mills in Edirne province

İl genelinde buğday alımları ve depolamaları, haziran ayında hasat ile birlikte başlamıştır. Temmuz ve ağustos ayında zararlı yoğunluğunun artmasında depo doluluk oranlarının en yüksek seviyeye ulaşılması ve ürün işlemelerinin en fazla oranda yapılması, eylül ayında meydana gelen düşüşün ilaçlamadan kaynaklandığı düşünülmektedir. Yine devam eden zararlı yoğunluğunun azalmasında depolarda ürün miktarındaki azalmalar ile birlikte havaların soğuması ve depolarda yeterli sıcaklığın bulunmamasının zararlı populasyonlarında yoğunluk farklılıklarına neden olduğunu kanısına varılmıştır.

Kucerova ve ark. (2005) tahıl depolarında S. granarius, C. ferrugineus, T. castaneum, O. surinamensis, T. stercorea, A. advena ve Cryptolestes sp'in en yaygın olarak mayıs ve haziran aylarında görüldüğ̈nü kaydetmişlerdir.

Arpa depolarında yapılan bir çalışmada ise, $R$. dominica, $S$. granarius, L. oryzae, C. ferrugineus, O. surinamensis, L. sericorne, Stegobium paniceum (L.) tespit edildiği ve mart ile mayıs aylarında en yüksek sayılara ulaştıkları bildirilmiştir (Belda ve Riudavets 2010)

Gönen ve Uzunköprü ilçeleri çeltik depolarında yaptıkları çalışmalar sonucunda zararlıların en yoğun olarak yaz aylarında görüldüğü kış aylarında populasyonlarda azalmaların saptandığı belirtilmiştir (Atabay ve ark. 2013).

\section{Buğday örneklerinde saptanan zararlı böceklerin bulunma oranları}

Alınan buğday örneklerinde Sitophilus spp. [Sitophilus granarius (L.), Sitophilus oryzae (L.)] \% 85,12, Oryzaephilus surinamensis (L.) \%6,78, Tribolium spp. [Tribolium confusum (Duv.), T. castaneum (Herbst.)] \% 3,95, Carpophilus dimidiatus \%2,26, Rhizopertha dominica (F.) \%1,32 ve diğer zararlılar [ Cryptolestes ferrugineus (Step.) ve Gnathocerus cornutus (Fab.) ] \% 0.57 olarak belirlenmiştir.

Yapılan çalışma ile, tüm depolarda Sitophilus spp. ile bulaşma saptanmış olup, toplamda 69 adet Sitophilus spp. ile U1 nolu depo bulaşmanın en yoğun olduğu depo olarak belirlenmiştir. Daha sonra sırasıyla Z1, Z7, U3, Z2, U2, U4, Z5, Z3, Z4, Z6, Z8, U5, TMO Lalapaşa, TMO Havsa ve TMO Merkez depolarının geldiği belirlenmiştir (Şekil 4).

Buğday ve pirinç biti erginleri yumurtalarını sağlam daneye bırakmakta, meydana gelen larvalarda dane içinde beslenerek agırlık, tohumluk değerinde kayıpların yanı sıra yoğun bulaşmalarda üründe küflenmeye ve kızışma meydana getirmektedirler (Aydın 2011). 


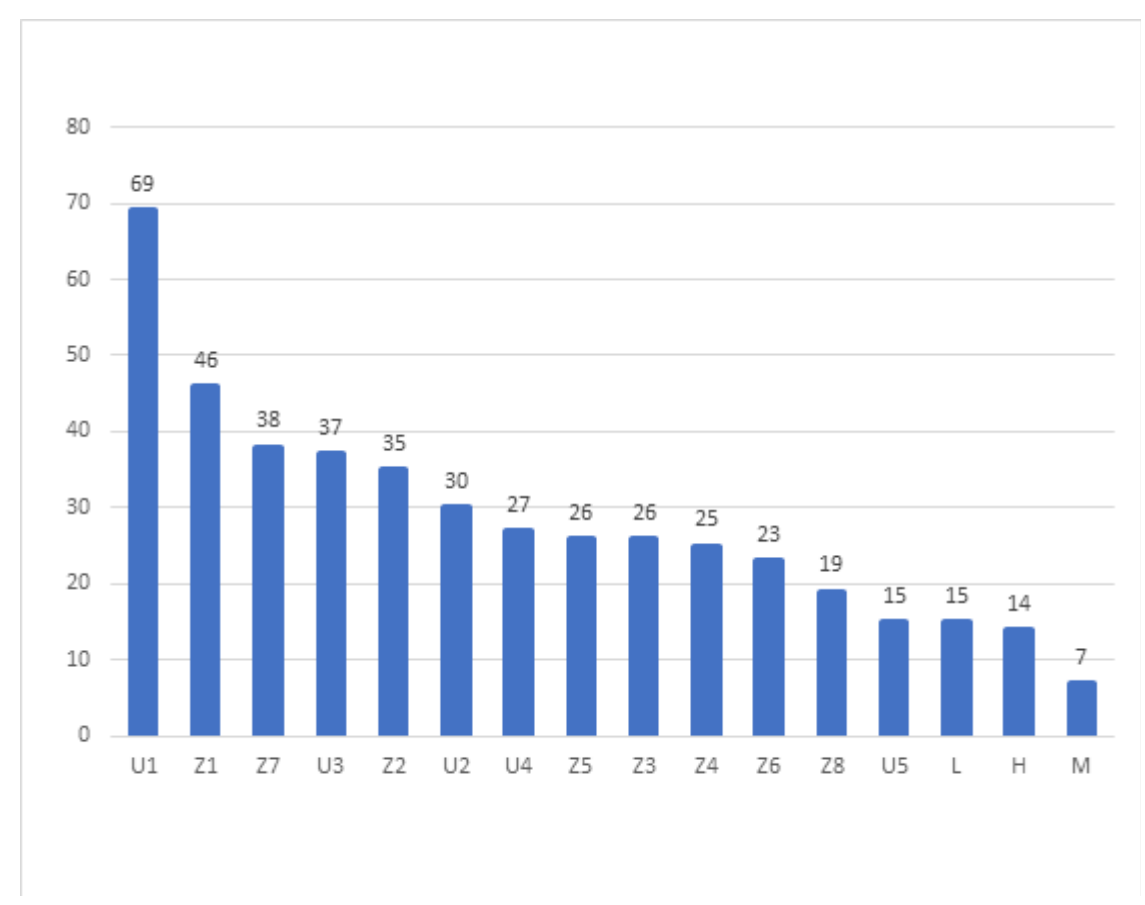

Şekil 4. Edirne ilinde buğday depolarında saptana Sitophilus spp.’ nin depolara gore bulunma sayıları (adet/kg.)

Figure 4. Rates of Sitophilus spp. detected in wheat warehouses and flour mills in Edirne province

Paula ve ark. (2002) Brezilya, Santa Catarina'daki çeltik depolama tesisinde bir yıllık çalışmaları sonucunda Sitophilus türlerini. \% 76 oranında tespit ettiklerini belirtmişlerdir.

Bağcı ve ark. (2014) Ankara İli ve çevre illerinde buğday ve arpa depolarında yaygın ve yoğun zararlı türün Liposcellis bostrychophila (Badonnel) olduğunu belirlemişlerdir.

Trematerra ve ark. (2004) Brezilya da yaptıkları çalışmada; çeltik depolama tesislerinden toplanan böcek türlerinin zaman ve mekana göre dağılımlarını incelemişler ve en yoğun tür olarak S. oryzae 'nin tespit edildiğini saptamışlardır.

Kucerova ve ark. (2005) Nisan-Eylül ayları arasında tahıl depolarındaki yürütmüş oldukları çalışmada; en yoğun türün $S$. granarius olduğunu ifade etmiştir.

Adıyaman ve Kahramanmaraş illerinde depolanmış buğdaylarda yürütülen çalışma ile T. confusum, P. subdepressus, $R$. dominica, S. oryzea, $O$. surinamensis, T. granarium ve P. İnterpunctella olmak üzere toplam 7 böcek türü tespit edildiği, $R$. dominica ve $T$. confusum'un bölgede saptanan en yaygın türler olduğun kaydedilmiştir (Işıkber ve ark. 2005).

\section{Kepek örneklerinde saptanan zararlı böceklerin bulunma oranları}

Un fabrikalarından alınan kepek örneklerinde Tribolium spp. [Tribolium confusum Du Val., T. castaneum (Herbst.)] \% 77,6 ve Oryzaephilus surinamensis (L.) \%22,4 olarak belirlenmiştir. Yapılan sürvey sonucunda un fabrikalarından alınan kepek numunelerinde en çok Tribolium türlerine rastlanılmıştır. En yoğun bulaşma 12 adet ile U5 nolu depo olurken sırasıyla; U1 nolu depoda 9 adet, U3 ve U2 nolu depoda 6' şar adet, U4 nolu depoda 5 adet Tribolium türüne rastlanmıştır (Şekil 5). 


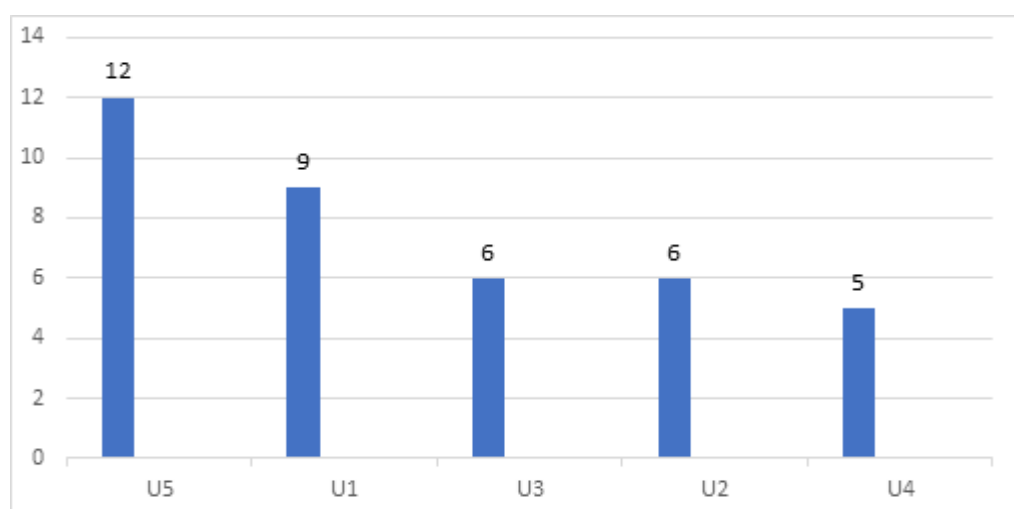

Şekil 5. Alınan kepek örneklerinde tespit edilen Tribolium spp’ nin bulunduğu depolar ve toplam birey sayıları (adet/ kg.)

Figure 5. Rates of Tribolium spp. detected in wheat warehouses and flour mills in Edirne province

Atabay ve ark. (2013) yaptıkları çalışma ile çeltik fabrikalarında kepeklerde yaygın ve yoğun olarak Tribolium türlerinin bulunduğunu saptamışlardır.

Ergül ve ark. (1972) Doğu ve Güneydoğu Anadolu Bölgesinde tetkike tabi tutulan illerde toplam olarak 491 ambar, 16 değirmen ve 11 un fabrikasında çalışma yapmış değirmenlerde yaygın olarak Tribolium spp. , $O$. surinamensis L. ve A. kuehniella Zel. tespit etmişlerdir.

Yücel (1988) Güneydoğu Anadolu Bölgesinde un fabrikaları ve değirmenlerinde bulunan zararlılar üzerine yaptığı çalışmada, bölgedeki fabrika ve değirmenlerde en yaygın ve en yoğun türün Tribolium confusum (Herbst.) toplam popülasyon içindeki payını $\% 95.3$ olarak belirlemiştir.

\section{Un örneklerinde saptanan zararlı böceklerin bulunma oranları}

Alınan un numunelerinde Ephestia kuehniella (Zell.) \% 57,75, Tribolium spp. [Tribolium confusum (Duv.), $T$. castaneum (Herbst.)] \% 38,03 ve diğer zararlılar [ Plodia interpunctella ve Oryzaephilus surinamensis (L.)] \% 4,22 olarak belirlenmiştir.

Lepidoptera takımı, Pyralidae familyasından Ephestia kuehniella (Zell.) 41 adet olarak tespit edilmiştir. Bunun 13 adedine $\mathrm{U} 2$ nolu depoda, 12 adedine $\mathrm{U} 1$ nolu depoda, 10 adedine $\mathrm{U} 4$ nolu depoda ve 6 adedine U3 nolu depoda rastlanmıştır (Şekil 4.19). Tamamı un örneklerinde tespit edilmiş olup en yoğun bulaşmaya sahip türdür.

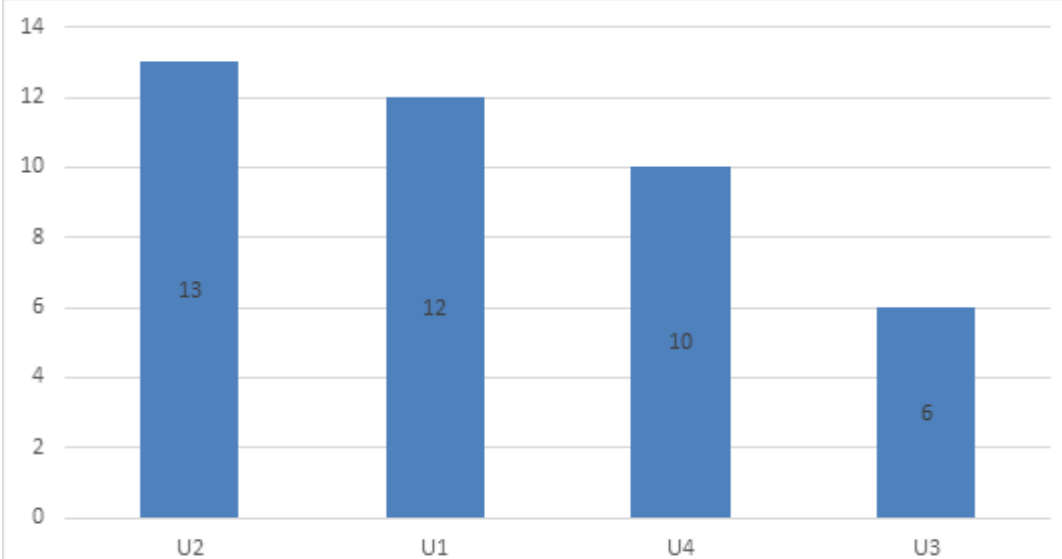

Şekil 6. Alınan un örneklerinde tespit edilen Ephestia kuehniella'nın bulunduğu depolar ve toplam birey sayıları (adet/kg.)

Figure 6. Rates of Ephestia kuehniella detected in wheat warehouses and flour mills in Edirne province

Çoşkuncu ve Kovancı (2005) yaptıkları çalışma sonucunda Bursa ili un fabrikalarında yaygın olarak $E$. kuehniella saptadıklarını, Pereira ve ark. (1998),ise Portekiz'de un fabrikalarında yaptıkları çalışmalarında $E$. kuehniella'nın fümigasyon yapılmayan fabrikalarda zararlının popülasyon yoğunluğunun çok yüksek bulunduğunu bildirmişlerdir.

Depolanmış buğdayın zararlısı olarak bilinen Değirmen güvesi [Ephestia kuehniella Zell.(Lep.:Pyralidae)] 
esas zararını unda yapmakla beraber zaman zaman tahıl depolarında sorun yaratmaktadır. Bu zararlının larvası unda çıkardığı ağ maddesiyle bunları birleştirmekte ve ürünün kalitesini bozmaktadır. Değirmen güvesi undan başka tahıl, kepek, ekmek, iç badem, yer fistığı, kuru meyve, bisküvi ve palamut meyvelerinde zararlıdır (Erakay 1974).

Yapılan çalışmada tüm depoların bulaşık olduğu saptanmıştır. Çeşitli araştırmacıların hububat depoları ve un fabrikalarında yaptıkları çalışmalarda da aynı zararlı türlerin varlığı kaydedilmiş fakat bulunma oranlarında farklılıkların bulunduğu belirlenmiştir. Bunun ise yapılan mücadele, depolanan buğday çeşiti, depolama türü ve bölge farklılıklarından ileri geldiği düşünülmektedir. Bu nedenle üreticilerin bu konuda özellikle bilgilendirilmelerin meydana gelecek kayıpların azaltılmasında çok önemli olduğu kanısına varılmıştır. 


\section{Kaynakça/References}

Anonim, 2018. 2017 Y1l1 Hububat Sektör Raporu.

http://www.tmo.gov.tr/Upload/Document/hububatsektorraporu2017.pdf (erişim tarihi 30.10.2018).

Atabay, S. 2013. Balıkesir Gönen İlçesi ve Çevresinde Depolanmış Çeltik ve Pirinç Fabrikalarında Saptanan Zararlı Böcekler Üzerine Araştırmalar. Yüksek Lisans Tezi, Namık Kemal Üniversitesi Fen Bilimleri Enstitüsü, Tekirdağ.

Aydın, V. 2011. Edirne ili Uzunköprü İlçesinde Çeltik ve Pirinç Fabrikalarında Saptanan Zararlı Böcekler Üzerine Araştırmalar. Yüksek Lisans Tezi, Namık Kemal Üniversitesi Fen Bilimleri Enstitüsü, Tekirdağ.

Bağcı, F., A. Yılmaz, S. Ertürk, 2014. Ankara İli Hububat Depolarında Bulunan Zararlı Böcek Türleri. Bitki Koruma Bülteni, 54 (1), $69-78$.

Belda, C., J. Riudavets, 2010. Distribution of Insect Pests and Their Natural Enemies in a Barley Pile. Proceedings of the 10th International Working Conference on Stored-product Protection. 27 June-2 July 2010, Estoril, Portugal, Julius-Kühn-Archiv, 425: 741-745.

Boxall, R. A. 2001. Post-harvest Losses to Insect-a World Overview International Biodeterioration \& Biodegradation 48, 137-152.

Coşkuncu, K. S., 2004. Bursa İli Un Fabrika ve Değirmenlerinde Zararlı Böcek Türleri. Uludağ Üniversitesi Ziraat Fakültesi Dergisi, 18(1): $33-44$

Coşkuncu, K. S, ve B. Kovancı, 2005. Bursa İli Un Fabrikalarında Zarar Yapan Ephestia kuehniella Zeller (Lepidoptera: Pyralidae)'nın Ergin Popülasyon Dalgalanması. Türkiye Entomoloji Dergisi, 29 (1): 35-48.

Donahaye, E. J. and E. Messer, 1992. Reduction in grain storage losses of small-scale farmers in tropical countries. Research Report RR-91-7, The Allan Shawn Feinstein World hunger Program, Brown University, USA.

Erakay, S., 1974. Ege Bölgesinde un ve undan mamul maddelerde bulunan zararlı böcekler üzerinde araștırmalar. Türkiye Cumhuriyeti Gıda, Tarım ve Hayvancılık Bakanlığı Zirai Mücadele ve Zirai Karantina Genel Müdürlüğü Araștırma Eserleri Serisi Teknik Bülten No. 23, 60s İzmir.

Ergül, C., N. Dörtbudak, ve A. Akülke, 1972. Doğu ve Güneydoğu Anadolu bölgelerinde hububat ve mamülleri ile bakliyat ambar zararlıları üzerinde araştırmalar. Bitki Koruma Bülteni, 12.129-143.

Gençtan, T, A. Balkan, 2005. Serin İklim Tahılları. Trakya Üniversitesi Tekirdağ Ziraat Fakültesi Tarla Bitkileri Bölümü, 120s, Tekirdağ

Ișıkber A A, Özdamar H Ü, Karcı A (2005). Kahramanmaraș ve Adıyaman İllerinde Depolanmıș Buğdaylar Üzerinde Rastlanan Böcek Türleri ve Bulaşma Oranları, KSÜ Fen ve Mühendislik Dergisi 8 (1), 107-113.

Kırtok, Y., 1997. Genel Tarla Bitkileri. Çukurova Üniversitesi Ziraat Fakültesi, Ders Kitabı No:30, Adana, 114s

Kucerova, Z., R. Aulicky, R., V. Stejskal, 2005. Outdoor Occurence of Stored-Product Pests (Coleoptera) in the Vicinity of a Grain Storage. Plant Protect. Sci., 41, 86-89.

Özdemir, A. 2015. Erzurum, Bayburt ve Erzincan İllerinde Toprak Mahsulleri Ofisi Depolarında Bulunan Hububat Zararlısı Böcekler. Yüksek Lisans Tezi, Atatürk Üniversitesi Fen Bilimleri Enstitüsü, Erzurum.

Paula, M. C. Z, S.M.N., and F.A. Lazzari, 2002. Insect Monitoring in Paddy Rice Storage Facility. In: Credland, P.F.A., Armitage, D.M., Bell, C.H., Cogan, P.M., Highley, E. (Eds), Proceedings of the Eighth, International Working Conference on Stored-product Protection, $22-26$ July 2002, York, UK, CAB International, Wallingford, UK, pp. 360-363.

Pereira, P., C. Adler \& M. Schöeller, 1998. The use of pheromone traps for monitoring Ephestia kuehniella Zeller (Lepidoptera: Pyralidae) and detection of parasitoids in flour mills. Integrated Protection of Stored Products. Proceedings of Meeting at 48 Zurich, Switzerland, 31 August-2 September,1997. Bulletin OILB/SROP, 21 (3): 111-117.

Stejskal, V. and J. Hubert, 2006. Arthropods as sources of contaminants of stored products: an overview. In: Proceedings of the Ninth International Working Conference on Stored-Product Protection. 2006. p. 15-18.

Trematerra, P, M.C.Z., Paula, A. Sciaretta , S.M.N. Lazzari, 2004. Spatio-Temporal Analysis of Insect Pest Infesting a Paddy Rice Storage Facility. Neotropical Entomology, 33 (4): 469-479.

Yücel, A. 1988. Güneydoğu Anadolu Bölgesi’nde Un Fabrikaları ve Un Değirmenlerinde Bulunan Zararlılar ve Zarar Durumları Üzerinde Ön Çalışmalar. Bitki Koruma Bülteni, 28 (1-2): 57-77. 